\title{
Microstructural Changes Due to Friction Stir Processing of Investment-Cast Ti-6Al-4V
}

\author{
A.L. PILCHAK, M.C. JUHAS, and J.C. WILLIAMS
}

DOI: $10.1007 / \mathrm{s} 11661-007-9195-5$

(C) The Minerals, Metals \& Materials Society and ASM International 2007

Erratum to: METALLURGICAL AND MATERIALS TRANSACTIONS A, Vol. 38A, No. 2, February 2007, pp. 401-08

DOI: $10.1007 / \mathrm{s} 11661-006-9061-\mathrm{x}$

THERE is an error in the first sentence, second paragraph on page 401 . The sentence should read as follows:

A FSW tool was used by Mishra and co-workers [10] to locally modify the microstructure of a monolithic plate of 7075-T651 aluminum, a technique referred to as friction stir processing (FSP).

\footnotetext{
A.L. PILCHAK, Graduate Research Associate, and J.C. WILLIAMS, Professor and Honda Chair, are with the Department of Materials Science and Engineering, The Ohio State University, Columbus, OH 43210, USA. Contact e-mail: pilchak.1@osu.edu M.C. JUHAS, Senior Assistant Dean for Diversity and Outreach, College of Engineering, and Research Scientist, Department of Materials Science and Engineering, The Ohio State University, Columbus, OH 43210, USA, is currently on leave as Program Director for Diversity and Outreach, Directorate for Engineering, National Science Foundation, Arlington, VA 22230, USA.

The online version of the original article can be found under doi:10.1007/s11661-006-9061-x.

Article published online June 14, 2007.
} 